\title{
GH treatment, BMI and different genotypes in patients with Prader-Willi syndrome and scoliosis: Is there any relationship?
}

\author{
Tiziana Greggi $^{1 *}$, E. Pipitone ${ }^{1}$, K. Martikos ${ }^{1}$, F. Lolli ${ }^{1}$, F. Vommaro ${ }^{1}$, E. Maredi ${ }^{1}$, M. Di Silvestre ${ }^{1}$,
} S. Giacomini ${ }^{1}$, L. Sangiorgi ${ }^{2}$

${ }^{1}$ Spine Surgery Department, Rizzoli Orthopaedic Institute-I.O.R., Bologna, Italy

${ }^{2}$ Medical Genetics, Rizzoli Orthopaedic Institute-I.O.R., Bologna, Italy

Email: "tiziana.greggi@ior.it

Received 25 August 2013; revised 25 September 2013; accepted 9 October 2013

Copyright (C) 2013 Tiziana Greggi et al. This is an open access article distributed under the Creative Commons Attribution License, which permits unrestricted use, distribution, and reproduction in any medium, provided the original work is properly cited.

\begin{abstract}
The purpose of this study is to try to find a protocol defining a clinical diagnostic procedure for the patients to be admitted to the authors' Institute to receive treatment for either suspected or confirmed diagnosis of spine deformity in Prader-Willi syndrome (PWS). The aim is to evaluate every subject from the diagnostic point of view, assessing variability of clinical expression and evolution of spinal deformity in the light of the related genetic aspects, thus providing a univocal protocol. The present series only includes patients (18 cases) with PWS, 7 hospitalized for surgical treatment of scoliosis, 11 followed-up at the authors' institute only for conservative treatment of scoliosis. Both BMI tracks (weight/height ${ }^{2}$ ) and BMI Z-score (only for children older than 2 years) were assessed. Moreover, the GH treatment was evaluated for each group of patients as follows: being administered, suspended or no treatment. Finally, the gene was compared with BMI. No relationship was observed either between GH treatment and mean BMI or between genetics and mean BMI. More patients should be seen by the authors to confirm or refute the current findings.
\end{abstract}

Keywords: Scoliosis; Prader-Willi; GH; BMI

\section{INTRODUCTION}

The PWS is a rare and complex genetic disorder considered the most common genetic cause of morbid obesity, first described by Prader et al. back in 1956 [1].

The prevalence reported in epidemiological studies

${ }^{*}$ Corresponding author. varies between 1 in 8000 and 1 in 134,000 whereas the number of births identified as being PWS cases varies between 1 in 15,000 and 1 in 30,000. In 2010, the European Organization for Rare Disease in partnership with Orphanet estimated the number of person living with PWS in Europe to be around 10.7 per 100,000 (1:9346) [2,3].

Genes associated with PWS are known to be expressed from chromosome 15 derived from the father, but not from the mother. Loss of the normal contribution from paternally inherited genes in this interval leads to the PWS phenotype, since maternal genes are normally inactivated. This type of genetic regulation dependent on the sex of the transmitting parent is termed genomic imprinting [4].

The three genetic mechanisms involved in PWS are: interstitial deletions of the paternal chromosome 15, which are of two classes differing by their total length (T1 deletion larger than T2 deletion) [5]; maternal uniparental disomy (mUPD, or two copies of chromosome 15 from mother and none from father), [6] which can be either hetero- or isodisomy (meaning two different maternal chromosomes or two copies of the same maternal chromosome), and imprinting defects [7] and translocations. Recently it has been suggested that additional factors such as maternal age, environmental variables causing genetic errors, the use of reproductive technologies and diagnostic methodology have influenced the previously recognized distribution of genetic subtypes, with mUPD occurring more frequently than previously recognized $[8,9]$.

In Italy PWS is related to deletion for $69 \%$ of the cases, mUPD for $30 \%$ [10].

The original consensus diagnostic criteria of Holm et al., 1993 [11] was recently revised [12] to indicate when genetic analysis should be performed [13]. 
In the foetus and newborn, PWS is generally characterized by decreased fetal movement, prenatal and postnatal hypotonia (or diminish muscular tone) and poor suckling, causing decreased movement, lethargy, abnormal cry, breathing difficulties requiring special feeding techniques and poor reflexes, and resulting in failure to thrive. Whereas hypotonia improves over time, and difficulties in feeding are replaced by normal calorie intake with a beginning of central obesity during the toddler years $[14,15]$.

Characteristic facial features including narrow bifrontal diameter with dolichocephaly (head disproportionally long and narrow), almond-shaped eyes with ocular defects (estropia, myopia), thin upper lip with down-turned mouth and thick saliva.

In preadolescence, mild to moderate mental deficiency, behavioral disorders (e.g. obsessive-compulsive characteristics, self-injury behavior, skin-picking, temper tantrums, manipulative behavior, impulsivity, stubbornness) and cognitive disabilities also become manifest and intensify with age. Musculoskeletal problems may also become apparent, such as scoliosis (abnormal back curvature) [16-20]. Hyperkyphotic deformity can be observed in nearly $40 \%$ of the patients [21-23].

The syndrome is associated with growth hormone deficiency (GHD). According to cross-sectional, prospective and retrospective studies, GHD prevalence ranged from $58 \%$ to $100 \%[24,25]$. Similar prevalence rates $(74 \%)$ were observed in the international, observational KIGS database [26].

Obesity is a primary cause of increased morbidity and premature mortality in PWS. It leads to complications such as type 2 diabetes mellitus, hypertension, atherosclerosis, hyperlipidemia, cardiovascular diseases, respiratory insufficiencies, thrombophlebitis, leg edema, and sleep apnea. Increased rates of scoliosis are also observed.

Although the pharmacological therapy with growth hormone (GH) provides satisfactory results, its impact on progression of spinal deformities still remains controversial $[21,27]$.

According to a study conducted in the UK population, mortality rate of individuals with PWS not treated with GH was estimated at 3\% per year between age 6 and 56 years and at $7 \%$ per year above 30 years of age. Epidemiological data from Italy noted 18 deaths over a 20 -year period of observation $(4.2 \%)$, occurring in both the pediatric and adult subjects (age range: 0.5 - 39.3). Causes of death in children are usually associated with respiratory infection or insufficiency, whereas mortality in adults is found to be primarily circulatory and/or respiratory failure [10].

The various different clinical and pathological conditions with onset during the pediatric and early adolescent age, and affecting the general aspect and health status, can change or delay treatment of spinal deformities and subsequently entail negative consequences in terms of life quality and expectation. Scoliosis is reported to require active treatment in $15 \%$ to $20 \%$ of the cases and to behave as an idiopathic scoliosis, with high risk of progression during adolescence $[1,22]$.

Absent, inadequate or delayed treatment of spinal deformities can jeopardize the patient's respiratory and cardiocirculatory "compliance", which is already severely compromised by the other remarkable phenotypic aspects of the syndrome.

\section{MATERIALS AND METHODS}

The present case series includes 18 patients, 11 of which (9 males and 3 females) were seen at the Rare Disease Outpatients' Unit for conservative treatment; mean age was 4.2 years (range, 0.5 to 16.1). Another 7 patients were surgically treated: they were 5 males and 2 females, aged 12.8 years on average (range, 10 to 14.6 years).

Regarding the patients' origin, $87 \%$ came from outside the region (Emilia-Romagna): $61 \%$ from the central southern area and 44\% from Latium, in particular (Figure 1).

For all of the 18 patients, both standard BMI (weight/ height ${ }^{2}$ ) and the BMI Z-score developed by the Centers for Disease Control and Prevention (CDC) were calculated. The latter is to be preferred when assessing children $[28,29]$ to allow for their classification into underweight/ normal weight/overweight/obesity (Table 1), although more recent studies tend to attach importance to the use of BMI also for younger patients [30]. As a matter of fact, the values of BMI Z-score are charted for specific

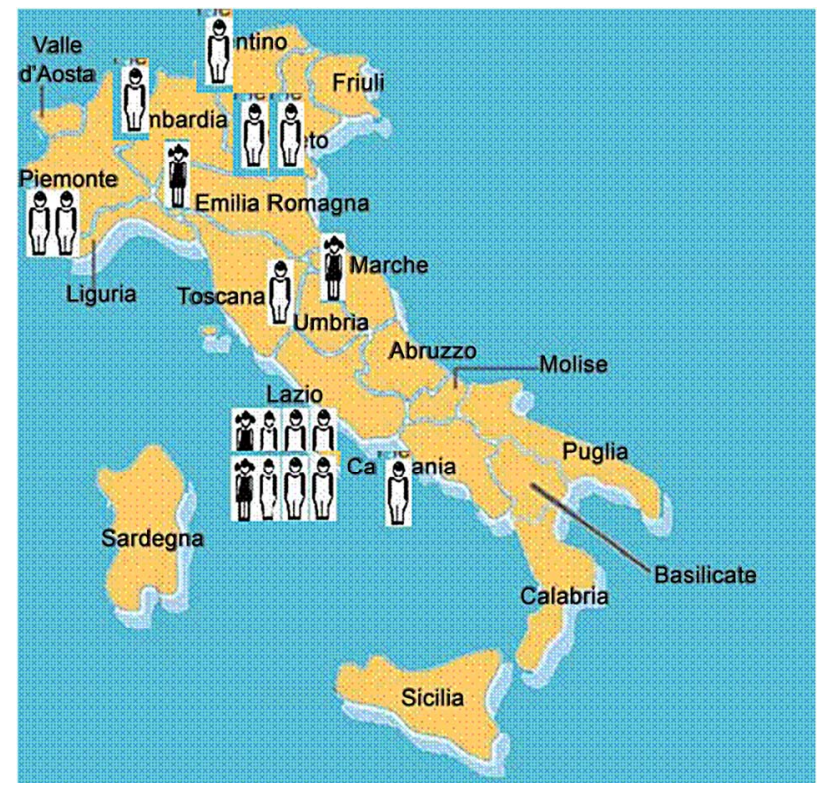

Figure 1. Patients' Origin Region of origin of the patients belonging to the series with PWS. 
Table 1. Weight categories corresponding to percentile ranges.

\begin{tabular}{cc}
\hline Weight Status Category & Percentile Range \\
\hline Underweight & Less than the 5th percentile \\
Healthy Weight & 5th percentile to less than the 85th percentile \\
Overweight & 85th to less than the 95th percentile \\
Obesity & Equal to or greater than the 95th percentile \\
\hline
\end{tabular}

Z-scores $(-2,-1.5,-1,-0.5,0,0.5,1,1.5,2)$, corresponding to as many different growth curves for the children. Scores are used to express the standard deviation from the mean calculated on the reference population. The corresponding percentiles in standard normal distribution are calculated from Z-scores; the different weight categories (underweight/normal weight/overweight/obesity) derive from the percentile ranges. Percentiles are plotted in "growth charts by age" (Figure 2) for each gender. Proceeding this way, the BMI of a specific child is plotted on the chart against the other children of the same sex and age.

Anyway, BMI Z-score, can be calculated only for patients older than 2 years and therefore could not have been applied in 5 cases, thus reducing the current case series - which is small, the study involving a rare disease and referring to a single diagnosis and treatment centreby $30 \%$ approximately. Therefore, both BMI indices were used.

The GH treatment was assessed in all of the 18 subjects: being administered, suspended or no treatment.

The genotype is known only for the group of $12 \mathrm{PW}$ patients conservatively treated at the outpatients' unit (deletion of chromosome 15 or uniparental disomy), since the genetic test was not routinely performed when the surgically-treated patients' data were recorded.

The purpose of the study was to evaluate the relationship between BMI and GH treatment and, only for the outpatients, the relationship between BMI and genotype. The two groups of cases were assessed both separately and as a whole. The statistical tests used were the following: either the Chi-square test or the Fisher's exact test when the BMI-Z score was calculated, and the Wilcoxon test to calculate the differences between the average values for the BMI.

\section{RESULTS}

Of the 12 outpatients with PWS (Table 2), 9 were males and 3 females; 87\% came from outside the Region (Emilia-Romagna): $61 \%$ from the central southern area, Latium in particular (44\%); 11 had received conservative treatment, 1 surgical treatment.

The BMI of the PW children seen at the Outpatients' Unit turned out to be 17.54 (range, 11.49 to 29.48), wherease the BMI Z-score was 0.7 (range, -0.7 to 1.7 ).

Their medical history revealed the presence, absence

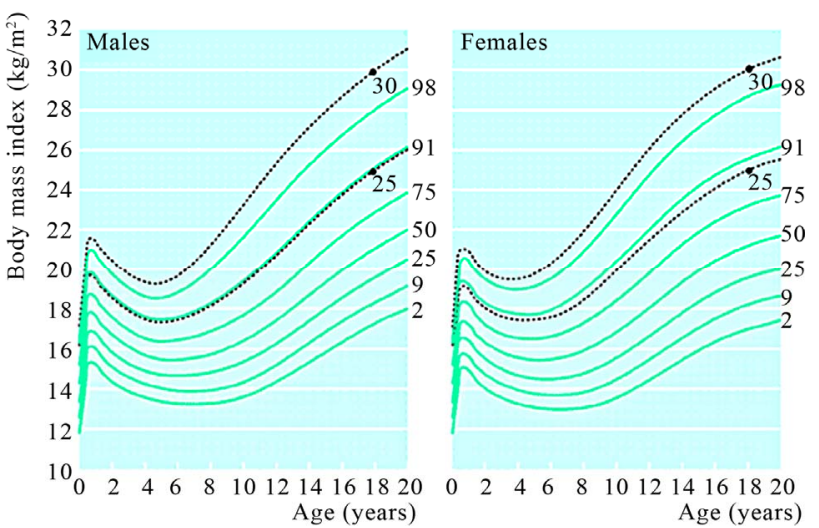

Figure 2. BMI for age and sex body mass index for age percentiles by sex.

Table 2. Characteristics of PWS outpatients.

\begin{tabular}{ll}
\hline Characteristics & Values \\
\hline Patients' number & $9 \mathrm{M}$ \\
by sex & $3 \mathrm{~F}$ \\
Mean age & 4.2 yrs (range, 0.5 to 16.1$)$ \\
BMI & 17.54 (range, 11.5 to 29.5$)$ \\
& 0.66 (range, -0.7 to 1.7$)$ \\
BMI Z-score & $70.4 \%$ percentile (range, $25.5 \%$ to $95.6 \%)$ \\
& 8 treated \\
GH & 2 suspended treatment \\
& 2 not recorded \\
Genotype & 9 microdeletion of chromosome 15 \\
& 3 uniparental disomy \\
\hline
\end{tabular}

of suspension of the GH treatment: GH had been administered to 8 patients, suspended in 2 cases and no information was available for the 2 remaining cases.

Many studies (references 1 to 9) refer to the GH treatment in PWS without reaching unambiguous conclusions.

The present case series showed a statistically significant $(p<0.05)$ difference in terms of mean BMI which proved to be lower in children receiving $\mathrm{GH}$ treatment $(16.8, \pm 1.1)$ than in those who had had it suspended $(24.7$, d.s. \pm 6.8 ) (Table 3).

In addition, genetics was compared with BMI as follows: mean BMI equal to 18 for the 9 patients with microdeletion of chromosome 15 versus mean BMI equal to 15 for the 3 patients with uniparental disomy. The difference between BMI in the 2 groups did not result to be statistically significant (Table 3).

Considering the other group of 7 PWS patients operated on for scoliosis (Table 4), 5 of them were males with mean age of 12.8 yrs (range, 10 to 14.6).

The BMI of the 7 patients with PW operated on for scoliosis turned out to be equal to 29.41 (range, 21.03 to 41.72), whereas the BMI Z-score was 1.8 (range, 0.51 to 2.77). This value was notably higher than that observed 
Table 3. BMI relationship with GH and genotype in PW outpatients.

\begin{tabular}{|c|c|c|c|}
\hline & GH treated & GH interrupted & $\mathrm{p}$ \\
\hline \multirow[t]{2}{*}{ Mean BMI } & $\begin{array}{c}16.8 \\
( \pm 1.1)\end{array}$ & $\begin{array}{c}24.7 \\
( \pm 6.8)\end{array}$ & 0.05 \\
\hline & $\begin{array}{l}\text { Microdeletion of } \\
\text { chromosome } 15\end{array}$ & Uniparental disomy & \\
\hline Mean BMI & $\begin{array}{c}18 \\
( \pm 4.1)\end{array}$ & $\begin{array}{c}15 \\
( \pm 2.8)\end{array}$ & n.s. \\
\hline
\end{tabular}

Table 4. Characteristics of PWS surgically-treated patients.

\begin{tabular}{ll}
\hline Characteristics & Values \\
\hline Patients' number & $5 \mathrm{M}$ \\
by sex & $2 \mathrm{~F}$ \\
Mean age & 12.8 yrs (range, 10 to 14.6$)$ \\
BMI & 29.41 (range, 21.0 to 41.7 ) \\
BMI Z-score & 1.8 (range 0.5 to 2.8 ). \\
GH & 4 treated \\
\hline
\end{tabular}

in outpatients who also were much younger.

The BMI Z-score could be calculated for all of the patients belonging to this group; subsequently, using growth charts by age percentiles, the weight categories could be assessed and the following results achieved: normal weight in 2 cases, overweight in 1 and obesity in 4 .

Focus was put on the relationship between weight categories (obesity and overweight were considered as a whole, due to the low number of subjects to be included in the latter) and the corresponding GH treatment: of the 4 cases receiving Gh treatment, 3 (75\%) were obese and one overweight; of the 3 who did not receive the GH treatment, 2 were normal weight $(75 \%)$ and 1 obese. The test proved to be not significant.

Besides, since surgery cannot be considered as an effect modifier of this relationship, outpatients and surgically-treated patients were assessed as a whole. In this case, the authors compared the average BMI for the 2 groups instead of the weight categories deriving from the BMI Z-score: no significant difference was found (Table 5).

\section{DISCUSSION AND CONCLUSIONS}

Before to begin GH treatment, many steps have to be accomplished, starting from genetic confirmation of PWS, On GH treatment regular clinical assessment of height, weight, BMI, body composition, pubertal status, scoliosis, and side effects every 2 - 6 months should be done. At cessation of $\mathrm{GH}$, treatment uncontrolled progression of obesity should be present in terms of how it has been reported in the International-Second Expert Meeting of the Comprehensive Care of Patients with PWS (2008) [31].
Table 5. Mean BMI relationship with GH in PWS patients.

\begin{tabular}{cccccc}
\hline & $\begin{array}{c}\text { GH } \\
\text { administered }\end{array}$ & $\begin{array}{c}\text { GH } \\
\text { suspended }\end{array}$ & $\begin{array}{c}\text { No GH } \\
\text { treatment }\end{array}$ & $\begin{array}{c}\text { GH } \\
\text { Not recorded }\end{array}$ & p \\
\hline Mean & 20.7 & 24.7 & 31.4 & 13.3 & \\
BMI & $( \pm 6.1)$ & $( \pm 6.8)$ & $( \pm 14.6)$ & $( \pm 2.6)$ & n.s. \\
\hline
\end{tabular}

The only report that state scoliosis evolution and GH treatment is a two-year open label study of Sode-Carlsen et al. (2011) [32]. This study reported that scoliosis progressed in six of 38 patients, whereas three patients had a decrease of Cobb angle of more than $5^{\circ}$. It is unclear if these observations are the results of GH treatment or the natural history of progression of scoliosis in PWS adults. Similar observations were reported for edema which is often seen in clinical studies of GH treatment in adults [33-35].

In our study, no significant difference in terms of BMI was observed between patients receiving $\mathrm{GH}$ treatment and patients who did not receive it. No relationship between GH treatment and mean BMI was seen. Anyway, additional studies can be performed creating a subgroup from the present case series which includes the patients younger than 2 yrs, and replacing the BMI with the BMI Z-score.

No relationship between genetics and mean BMI was found in the outpatients' group.

However, our case series is being too small, as it always happens with rare diseases, and for recording of data incomplete, more patients need to be examined by the authors to confirm or refute these findings.

\section{REFERENCES}

[1] Grugni, G., Crinò, A., Bertocco, P. and Marzullo, P. (2009) Body fat excess and stimulate growth hormone levels in adult patients with Prader-Willi syndrome. American Journal of Medical Genetics, 149A, 726-731.

[2] Orphanet (2010). Prevalence of rare diseases: Bibliographic data.

[3] Feigerlová, E., Diene, G., Conte-Auriol, F., Molinas, C., Gennero, I., Salles, J.P., Arnaud, C. and Tauber, M. (2008) Hyperghrelinemia precedes obesity in Prader-Willi syndrome. The Journal of Clinical Endocrinology \& Metabolism, 93, 2800-2805.

[4] Horsthemke, B. and Wagstaff, J. (2008) Mechanisms of imprinting of the Prader-Willi/Angelman region. American Journal of Medical Genetics, 146A, 2041-2052. http://dx.doi.org/10.1002/ajmg.a.32364

[5] Ledbetter, D.H., Riccardi, V.M., Airhart, S.D., Strobel, R.J., Keenan, B.S. and Crawford, J.D. (1981) Deletions of chromosome 15 as a cause of the Prader-Willi syndrome. The New England Journal of Medicine, 304, 325-329. http://dx.doi.org/10.1056/NEJM198102053040604

[6] Nicholls, R.D., Knoll, J.H., Butler, M.G., Karam, S. and Lalande, M. (1989) Genetic imprinting suggested by ma- 
ternal heterodisomy in nondeletion Prader-Willi syndrome. Nature, 342, 281-285.

http://dx.doi.org/10.1038/342281a0

[7] Buiting, K., Saitoh, S., Gross, S., Dittrich, B., Schwartz, S., Nicholls, R.D., et al. (1995) Inherited microdeletions in the Angelman and Prader-Willi syndromes define an imprinting centre on human chromosome 15. Nature Genetics, 9, 395-400. http://dx.doi.org/10.1038/ng0495-395

[8] Sinnema, M., van Roozendaal, K.E., Maaskant, M.A., Smeets, H.J., Engelen, J.J., Jonker-Houben, N., et al. (2010) Different distribution of the genetic subtypes of the Prader-Willi syndrome in the elderly. European Journal of Human Genetics, 18, 993-998.

http://dx.doi.org/10.1038/ejhg.2010.67

[9] Whittington, J.E., Butler, J.V. and Holland, A.J. (2007) Changing rates of genetic subtypes of Prader-Willi syndrome in the UK. European Journal of Human Genetics, 15, 127-130. http://dx.doi.org/10.1038/sj.ejhg.5201716

[10] Grugni, G., Crino, A., Bosio, L., Corrias, A., Cuttini, M., De Toni, T., et al. (2008) The Italian National Survey for Prader-Willi syndrome: An epidemiologic study. American Journal of Medical Genetics, 146, 861-872. http://dx.doi.org/10.1002/ajmg.a.32133

[11] Holm, V.A., Cassidy, S.B., Butler, M.G., Hanchett, J.M., Greenswag, L.R., Whitman, B.Y., et al. (1993) PraderWilli syndrome: Consensus diagnostic criteria. Pediatrics, 91, 398-402.

[12] Gunay-Aygun, M., Schwartz, S., Heeger, S., O’Riordan, M.A. and Cassidy, S.B. (2001) The changing purpose of Prader-Willi syndrome clinical diagnostic criteria and proposed revised criteria. Pediatrics, 108, E92. http://dx.doi.org/10.1542/peds.108.5.e92

[13] Goldstone, A.P., Holland, A.J., Hauffa, B.P., Hokken-Koelega, A.C. and Tauber, M. (2008) Recommendations for the diagnosis and management of Prader-Willi syndrome. The Journal of Clinical Endocrinology \& Metabolism, 93, 4183-4197. http://dx.doi.org/10.1210/jc.2008-0649

[14] Fillion, M., Deal, C. and Van Vliet, G. (2009) Retrospective study of the potential benefits and adverse events during growth hormone treatment in children with PraderWilli syndrome. Journal of Pediatrics, 154, 230-233.

[15] Lin, H.Y., Lin, S.P., Tsai, L.P., Chao, M.C., Chen, M.R., Chuang, C.K., Huang, C.Y., Tsai, F.J., Chou, I.C., Chiu, P.C., Huang, C.H., Yen, J.L., Lin, J.L. and Kuo, P.L. (2008) Effects of growth hormone treatment on height, weight, and obesity in Taiwanese patients with Prader-Willi syndrome. Journal of the Chinese Medical Association, 71, 305-309.

[16] de Lind van Wijngaarden, R.F., de Klerk, L.W., Festen, D.A. and Hokken-Koelega, A.C. (2008) Scoliosis in Prader-Willi syndrome: Prevalence, effects of age, gender, body mass index, lean body mass and genotype. Archives of Disease in Childhood, 93, 1012-1016. http://dx.doi.org/10.1136/adc.2007.123836

[17] Nakamura, Y., Nagai, T., Iida, T., Ozeki, S. and Nohara, Y. (2009) Epidemiological aspects of scoliosis in a cohort of Japanese patients with Prader-Willi syndrome. Spine Journal, 9, 809-816. http://dx.doi.org/10.1016/j.spinee.2009.06.017
[18] Sinnema, M., Maaskant, M.A., van Schrojenstein Lantman-de Valk, H.M., Caroline, V.N.I., Drent, M.L., Curfs, L.M., et al. (2011) Physical health problems in adults with Prader-Willi syndrome. American Journal of Medical Genetics, 155, 2112-2124. http://dx.doi.org/10.1002/ajmg.a.34171

[19] Butler, M.G., Haber, L., Mernaugh, R., Carlson, M.G., Price, R. and Feurer, I.D. (2001) Decreased bone mineral density in Prader-Willi syndrome: Comparison with obese subjects. American Journal of Medical Genetics, 103, 216-222. http://dx.doi.org/10.1002/ajmg.1556

[20] Kroonen, L.T., Herman, M., Pizzutillo, P.D. and Macewen, G.D. (2006) Prader-Willi Syndrome: Clinical concerns for the orthopaedic surgeon. Journal of Pediatric Orthopaedics, 26, 673-679. http://dx.doi.org/10.1097/01.bpo.0000226282.01202.4f

[21] Festen, D.A., de Lind van Wijngaarden, R., van Eekelen, M., Otten, B.J., Wit, J.M., Duivenvoorden, H.J. and Hokken-Koelega, A.C. (2008) Randomized controlled GH trial: Effects on anthropometry, body composition and body proportions in a large group of children with Prader-Willi syndrome. Clinical Endocrinology, 69, 443-451.

[22] Crinò, A., Di Giorgio, G., Schiaffini, R., Fierabracci, A., Spera, S., Maggioni, A. and Gattinara, G.C. (2008) Central precocious puberty and growth hormone deficiency in a boy with Prader-Willi syndrome. European Journal of Pediatrics, 167, 1455-1458.

[23] Galassetti, P., Saetrum Opgaard, O., Cassidy, S.B. and Pontello, A. (2007) Nutrient intake and body composition variables in Prader-Willi syndrome-Effect of growth hormone supplementation and genetic subtype. Journal of Pediatric Endocrinology and Metabolism, 20, 491-500.

[24] Costeff, H., Holm, V.A., Ruvalcaba, R. and Shaver, J. (1990) Growth hormone secretion in Prader-Willi syndrome. Acta paediatrica Scandinavica, 79, 1059-1062. http://dx.doi.org/10.1111/j.1651-2227.1990.tb11383.x

[25] Myers, S.E., Whitman, B.Y., Carrel, A.L., Moerchen, V., Bekx, M.T. and Allen, D.B. (2007) Two years of growth hormone therapy in young children with Prader-Willi syndrome: Physical and neurodevelopmental benefits. American Journal of Medical Genetics, 143, 443-448. http://dx.doi.org/10.1002/ajmg.a.31468

[26] Tauber, M. and Cutfield, W. (2007) KIGS highlights: Growth hormone treatment in Prader-Willi Syndrome. Hormone Research, 68, 48-50.

[27] Caixàs, A., Giménez-Palop, O., Broch, M., Vilardell, C., Megía, A., Simón, I.,Giménez-Pérez, G., Mauricio, D., Vendrell, J., Richart, C. and González-Clemente, J.M. (2008) Adult subjects with Prader-Willi syndrome show more low-grade systemic inflammation than matched obese subjects. Journal of Endocrinological Investigation, 31, 169175.

[28] Frankenfield et al. (2001) Limits of body mass index to detect obesity and predict body composition. Nutrition, 17, 26-30. http://dx.doi.org/10.1016/S0899-9007(00)00471-8

[29] Deurenberg-Yap et al. (2000) The paradox of low body mass index and high body fat percentage among Chinese, Malays, and Indians in Singapore. International Journal 
of Obesity and Related Metabolic Disorders, 24, 10111017. http://dx.doi.org/10.1038/sj.ijo.0801353

[30] Berkey, C.S. and Colditz, G.A. (2007) Adiposity in adolescents: Change in actual BMI works better than change in BMI z score for longitudinal studies. Annals of Epidemiology, 17, 44-50.

[31] Goldstone, A.P., Holland, A.J., Hauffa, B.P., HokkenKoelega, A.C., Tauber, M. and Speakers Contributors at the Second Expert Meeting of the Comprehensive Care of Patients with PWS (2008) Recommendations for the diagnosis and management of Prader-Willi syndrome. The Journal of Clinical Endocrinology \& Metabolism, 93, 4183-4197.

[32] Sode-Carlsen, R., Farholt, S., Rabben, K.F., Bollerslev, J., Schreiner, T., Jurik, A.G., et al. (2010) One year of growth hormone treatment in adults with Prader-Willi syndrome improves body composition: Results from a randomized, placebo-controlled study. The Journal of Clinical Endocrinology \& Metabolism, 95, 4943-4950. http://dx.doi.org/10.1210/jc.2010-0907
[33] Hoybye, C., Hilding, A., Jacobsson, H. and Thoren, M. (2003) Growth hormone treatment improves body composition in adults with Prader-Willi syndrome. Clinical Endocrinology, 58, 653-661. http://dx.doi.org/10.1046/j.1365-2265.2003.01769.x

[34] Bertella, L., Mori, I., Grugni, G., Pignatti, R., Ceriani, F., Molinari, E., et al. (2007) Quality of life and psychological well-being in GH-treated, adult PWS patients: A longitudinal study. Journal of Intellectual Disability Research, 51, 302-311. http://dx.doi.org/10.1111/j.1365-2788.2006.00878.x

[35] Mogul, H.R., Lee, P.D., Whitman, B.Y., Zipf, W.B., Frey, M., Myers, S., et al. (2008) Growth hormone treatment of adults with Prader-Willi syndrome and growth hormone deficiency improves lean body mass, fractional body fat, and serum triiodothyronine without glucose impairment: results from the United States multicenter trial. The Journal of Clinical Endocrinology \& Metabolism, 93, 12381245. http://dx.doi.org/10.1210/jc.2007-2212 